\title{
Description of the early stages of Anomalipus plebejus plebejulus (Coleoptera: Tenebrionidae) from Zimbabwe with notes on the classification of the Opatrinae
}

\author{
DARIUSZ IWAN ${ }^{1}$ and STANISLAV BEČVÁ $\check{R}^{2}$ \\ ${ }^{1}$ Museum and Institute of Zoology, Polish Academy of Sciences, Wilcza 64, 00-679 Warszawa, Poland; \\ e-mail: darek@robal.miiz.waw.pl \\ ${ }^{2}$ Institute of Entomology, Czech Academy of Sciences, Branišovská 31, 37005 České Budějovice, Czech Republic; \\ e-mail: becvar@entu.cas.cz
}

Key words. Coleoptera, Tenebrionidae, Opatrinae, Tenebrioninae, Platynotini, Anomalipus, immature stages, classification, South Africa

\begin{abstract}
Immature stages of a South African tenebrionid beetle, Anomalipus plebejus plebejulus Endrödy-Younga, 1988, of the tribe Platynotini are described and illustrated. This account is the first modern description of the egg and first and older larval instars of the genus Anomalipus and the subtribe Anomalipina. The significance of larval characters of Anomalipus and other relevant taxa for classification of the subfamily Opatrinae sensu Medvedev (1968) [= "opatrine lineage: Opatrini" sensu Doyen \& Tschinkel (1982)] are discussed. A synopsis of Platynotini larvae is presented.
\end{abstract}

\section{INTRODUCTION}

Adults of the genus Anomalipus Latreille, 1846 were reviewed by Endrödy-Younga in his excellent monograph in 1988. He recognised 51 species, 26 subspecies and 22 infrasubspecific forms living in the South and the East of the Afrotropical region. A cladistic analysis of the Anomalipus species was not carried out, however, the kinship of species-groups was studied and presented in the form of a phylogenetic tree. The genus was divided into 16 species-groups of four phylogenetic lineages based on combinations of several states of three morphological characters. Although observations on the production of sound and mating behaviour in 11 species supported this systematic arrangement neither the lineages nor the species-groups were referred to formal taxonomic categories.

In her correspondence, Dr. L. Prozesky-Schulze informed the authors that despite the great structural variability of the adults of Anomalipus species, the larvae are rather uniform in appearance. She was able to divide them into 6 species-groups. She indexed her Anomalipus material under temporary names as no species taxonomy of the genus was available to her. Because the revision of the genus appeared too late for her work, her study on Anomalipus preimaginal stages has never been published.

In 1999, the authors obtained several larvae of Anomalipus that were impossible to place in the Blapimorpha group using either Skopin's (1964) or Watt's (1974) key. This is a further case of the problem discussed by Schulze (1969), of some taxa from South Africa not fiting into the current larval system.

Even if the species of Anomalipus are easily kept and reared in the laboratory (Endrödy-Younga, 1988), this study presents the first modern description of the imma- ture stages of this genus. Further larval descriptions from each Anomalipus species group recognised are needed to test the congruence of larval morphological characters with the evolutionary trends deduced from adults.

\section{HISTORY OF THE PLATYNOTINI LARVAE}

The larva of Anomalipus plebejus Péringuey was the first described larva of a tenebrionid placed in the Platynotini. Jack's (1917) description is very brief, however he indicates fossorially developed anterior legs and smooth egg-shaped anal segment (illustrated in two projections) with pseudopodia missing. It is certain that he correctly assigned his larva to the genus Anomalipus. Additional valuable observations of this author are the relatively large size of the egg $(4.25 \times 2.25 \mathrm{~mm})$, the length of the larva (up to $50 \mathrm{~mm}$ ) and that "...the adults emerge and the ova are laid at the commencement of the rains."

The first modern descriptions of platynotine larvae are those of Schulze (1962): Gonopus (Gonopus) tibialis (F.) and $G$. (Gonopus) agrestis Fåhraeus from South Africa. At the end she wrote: "A following paper dealing with the genus Anomalipus will contain a comparative study of the genera Gonopus Latreille, Zophodes Fåhraeus and Anomalipus Latreille of the Platynotini". The next year, Schulze (1963) published her study on the Stizopina, a subtribe of the Opatrini. The introduction of this paper contains a short general review of the main traits found in the larvae of the different tribes of Tenebrionidae from southern Africa. She noticed that the ninth abdominal sternum is reduced to a small appendage in Anomalipus larvae, and the punctures and deep holes on the head, the thorax and last two segments may be transformed into sensory capsules. In the preface Schulze wrote: "Papers on the Anomalipina of the Platynotini, the Drosochrini 
and the Zophosini are in preparation." At that time Koch was undertaking a taxonomic study of the genus Anomalipus, which was never published. Because of this Schultze did not publish her study of larval morphology of the Anomalipina (private correspondence with Dr. L. Prozesky-Schulze) but her publications on the Drosochrini and the Zophosini appeared in 1968 and 1974, respectively. In 1964 Schulze described larvae of the following Platynotini species from southern Africa: Bantodemus zulu Koch, Quadrideres femineus (Lesne) and Zophodes fitzsimonsi Koch. Later in 1978 she reviewed all known larvae of the genus Gonopus, adding descriptions of $G$. (Gonopus) angusticostis Gebien, G. (Agonopus) hirtipes Fåhraeus, G. (Agonopus) pliciventris Gebien and $G$. (Agonopus) transvaalensis Schulze. She showed that there are obvious morphological differences between the subgenera Gonopus and Agonopus associated with the ecology of these taxa.

Skopin (1972) added an interesting description of a tenebrionid from Nepal based on single larva tentatively identified as Pseudoblaps ampliata Fairmaire.

In 1995 Iwan described the larvae of Opatrinus aciculatus LeConte, $O$. gibbicollis Mulsant \& Rey and $O$. minimus (Palisot de Beauvois) from Panama and North America. His work increased the total number of descriptions of species of Platynotini larvae to 14 . The Anomalipina, Gonopina and Platynotina, all subtribes recognised by Koch (1956), are represented in this sample by one, six and seven species respectively. Nevertheless, preimaginal stages of the great majority of Platynotini genera and nearly 370 species are unknown.

\section{DESCRIPTION}

\section{Anomalipus plebejus plebejulus Endrödy-Younga, 1988}

Anomalipus plebejus Péringuey, 1896: 169. - Jack 1917: 91; Gebien 1938: 409 [446]; Keleinikova 1968: 208.

Anomalipus plebejus plebejulus Endrödy-Younga, 1988: 65.

The description is based on a later instar larva, $21.6 \mathrm{~mm}$ long, $2.0 \mathrm{~mm}$ wide, head capsule $1.8 \mathrm{~mm}$ broad. Remaining two later instar larvae were also examined and only variability of head and pronotal pits was found. Body fairly strongly sclerotized, subcylindrical, segments transverse to subquadrate, no constriction between segments. Cuticle ivory to light brown, glabrous; head, pronotum and ninth abdominal tergum darker.

Head (Figs 1, 21-22). Prognathous, weakly but distinctly retracted into prothorax (about $4 / 5$ length of epicranial stem). Cranium transverse, slightly convex, narrower than pronotum, sides rounded. Surface of frontoclypeal region and cranial plates with irregularly distributed fairly larges pores. Epicranial suture Y-shaped; epicranial stem short, about 5 times shorter than length of head capsule (measured from occipital foramen to frontoclypeal suture); frontal arms extend to antennal insertion; an additional oblique anteromedial ecdysial line branches off from each arm and extends toward the middle of frontoclypeal suture. Cranial setae fine, erect; one pair just behind frontoclypeal suture, two pairs near to stemmata and one pair on genae. Median endocarina absent. Antennae 3-segmented (Fig. 2), second antennomere is 2.0 times longer than wide and about 2.5 times longer than first, bearing apically a circlet of six subtriangular parts of subdivided sensillum surrounding base of apical segment; segment 3 minute, about 1/5 diameter of second, bearing subapical circlet of three short setae and a stout, longer apical seta; antennal insertion lateral, separated from mandible by a narrow strip of membrane. Stemmata 5 on each side; an ocular spot composed of two nearly fused stemmata arranged dorsally on anterior portion of epicranial plate and a transverse row of three fused stemmata antero-laterad from latter. Laterally, just before pronotal margin, each epicranial plate with 2 or 3 deep pits (additional 1-5 pits on each side of prothorax); patterns of their distribution variable (Fig. 19), they vary between individuals and may also differ on the two sides of the same specimen. Frontoclypeal suture distinct, epistomal ridge emarginate. Clypeus trapezoidal (Figs 3 and 4), at base 2.5 times wider than long; postclypeus with three pairs of setae arranged nearly transversally. Labrum transverse, weakly emarginate, with single pair of long medio -dorsal setae and with four long setae and eight short spines on each side along anterior margin. Epipharynx transverse-ovate with a pair of short spines in centre, two lateral setose patches below it, and strongly sclerotized, triangular pair of posterior plates. Mandibles asymmetrical, protruding laterally (Figs 8-11); their bifid apices strongly sclerotised and dark; left mandible with a triangular premolar tooth and a small tooth on base of molar part; right mola reduced, premolar part prominent with irregular margin; prostheca absent; basolateral portion of dorsal surface uniformly sclerotized without membranous area; outer margin ventrally with elongated excavation - an antennal groove; both mandibles with two setae near base of ventral antennal excavation and one seta near its apex. Maxilla (Fig. 7) with welldeveloped membranous articulating area; cardo transverse; elongate stipes bears 4 long setae: one at base and 3 anterolaterally; maxillary palpus 3 -segmented, first segment subquadrate, second twice as long as first bearing three setae anteriorly, segment 3 conical, slightly longer than first, with sensory area on apex; mala with its inner surface densely covered by strong spines, and slightly notched at inner margin. Labium with distinct prementum, mentum and submentum, gula not welldeveloped (Fig. 13); transverse prementum bears a pair of setae in centre, ligula twice shorter than first labial segment, with two setae on tip, labial palps 2-segmented, second segment conical, with sensory area on apex (Figs 5-6); mentum elongated, with a pair of setae at base and 2 pairs of longer setae lateromedially; trapezoidal submentum bears 6 setae anteriorly; gular sutures extend only to half length between base of submentum and occipital foramen; hypostomal rods absent. Hypopharynx densely setose medially, with tricuspidate and only slightly elongated hypopharyngeal sclerome, hypopharyngeal bracon (a transverse bar between hypopharynx and cranium) present. 

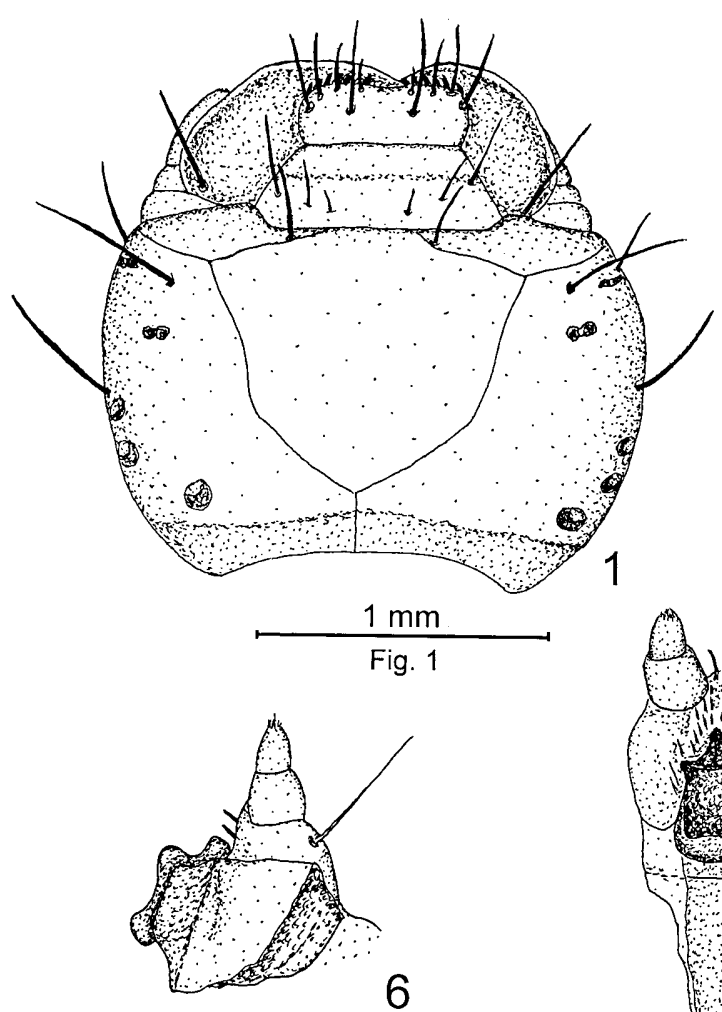

6
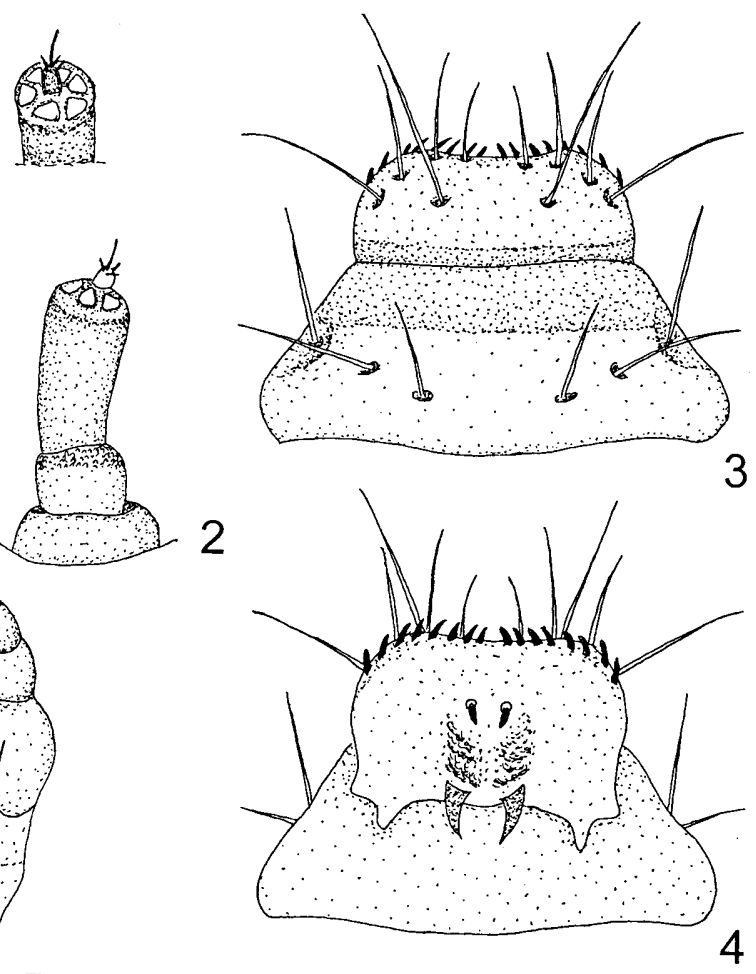

5
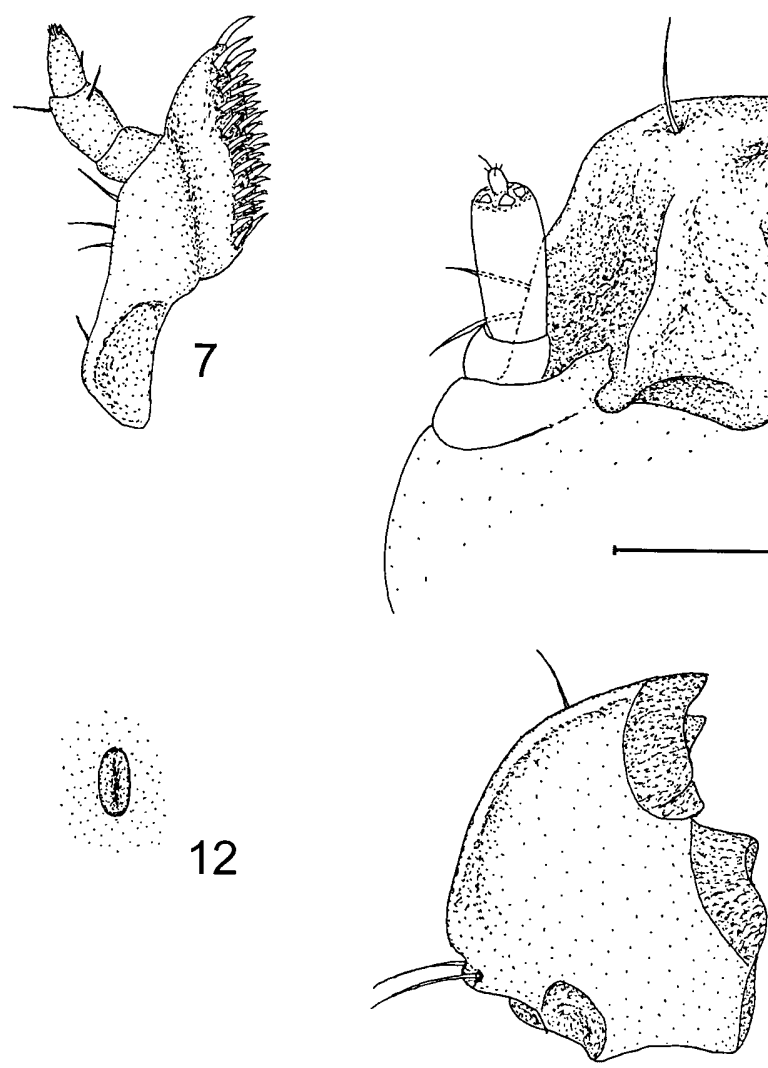

11
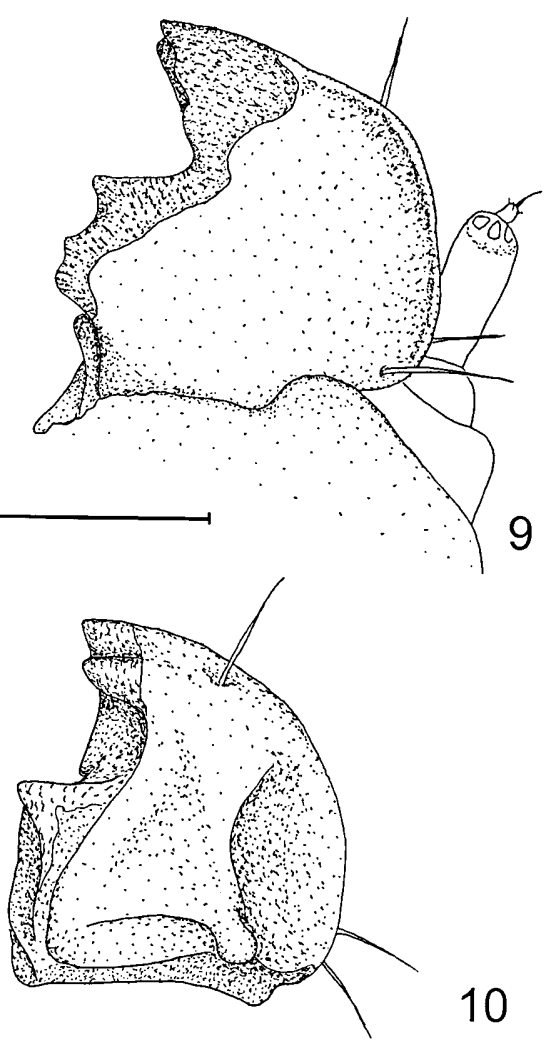

Figs 1-12: Anomalipus plebejus plebejulus. 1 - head, dorsal view; 2 - right antenna in dorsal view and apical part in subapical view showing arrangement of subdivided sensillum; 3 - dorsal and 4 - ventral view of labrum and clypeus; 5 - dorsal and 6 - lateral view of labium; 7 - dorsal view of maxilla; 8 - ventral and 9 - dorsal view of right mandible; 10 - ventral and 11 - dorsal view of left mandible; 12 - mesonotal spiracle. 


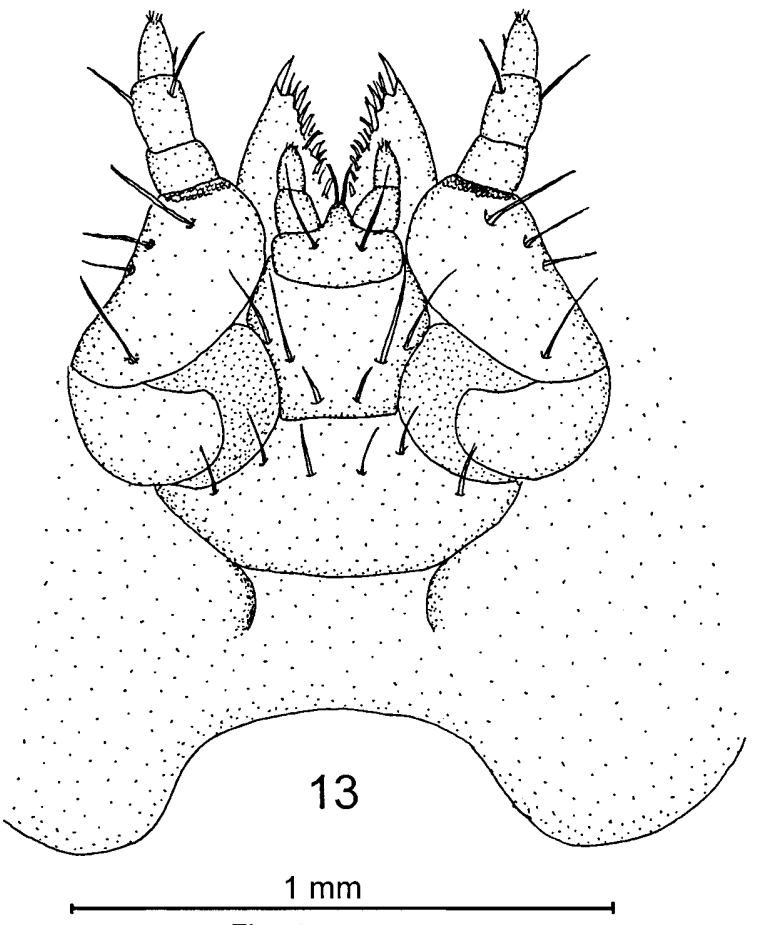

Figs 13 and 14

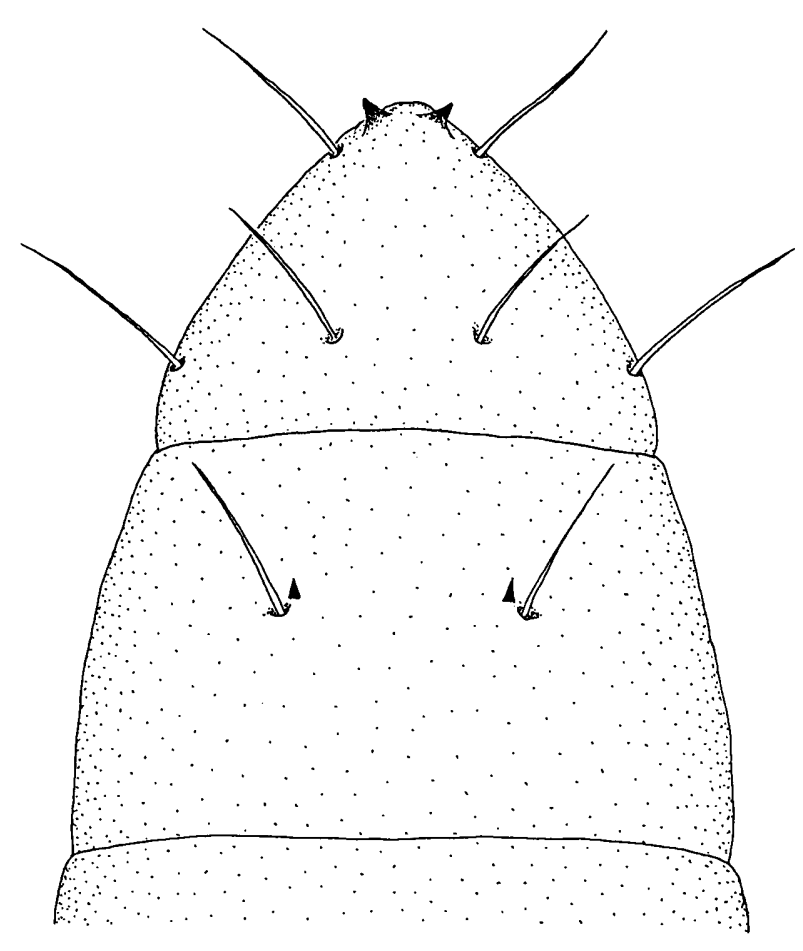

14

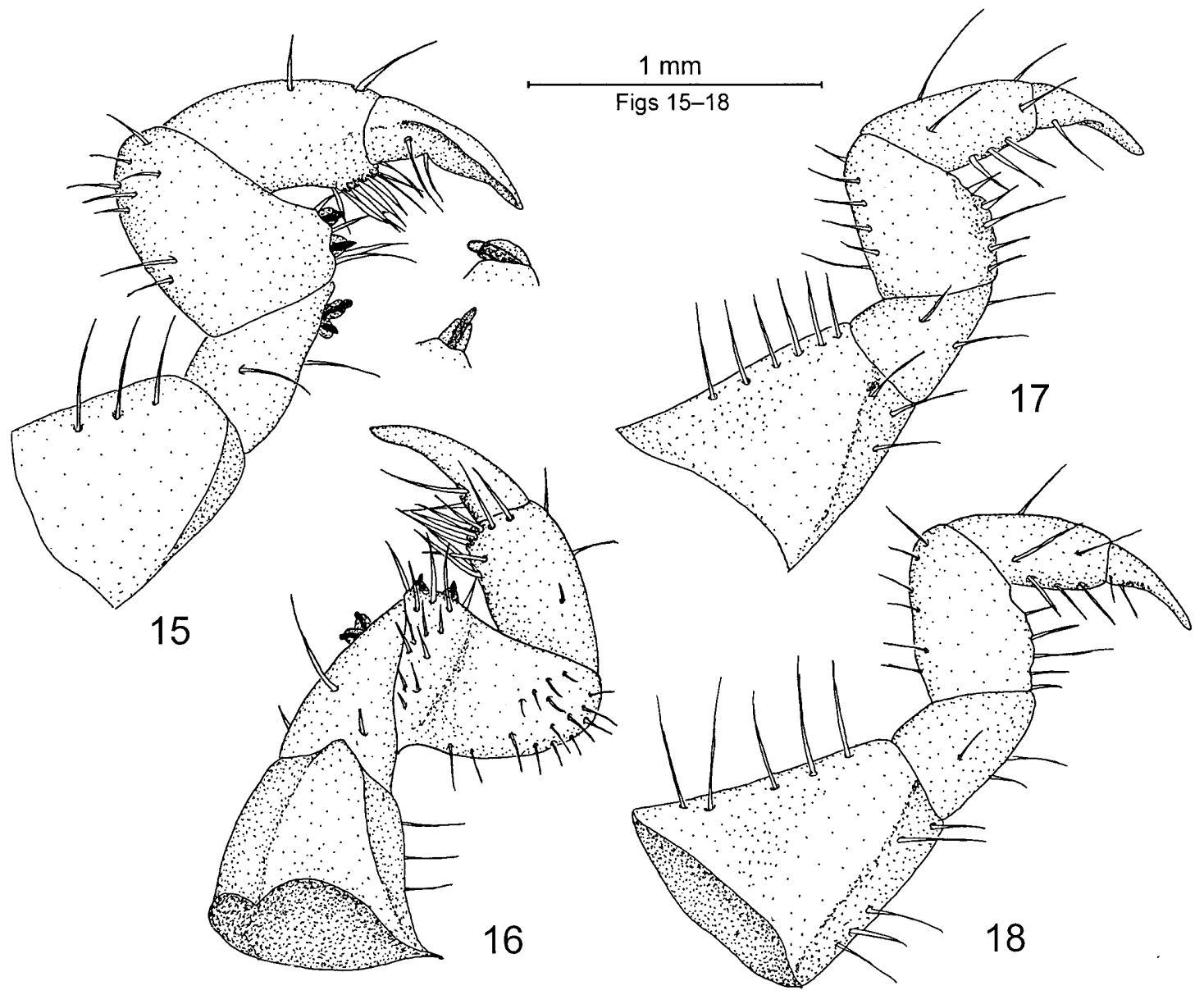

Figs 13-18: Anomalipus plebejus plebejulus. 13 - labiomaxillary complex, ventral view; 14 - eighth and ninth abdominal tergum of first instar; 15 - dorsal and 16 - ventral view of left fore leg (with detail of tubercles); 17 - dorsal and 18 - ventral view of left mid leg. 

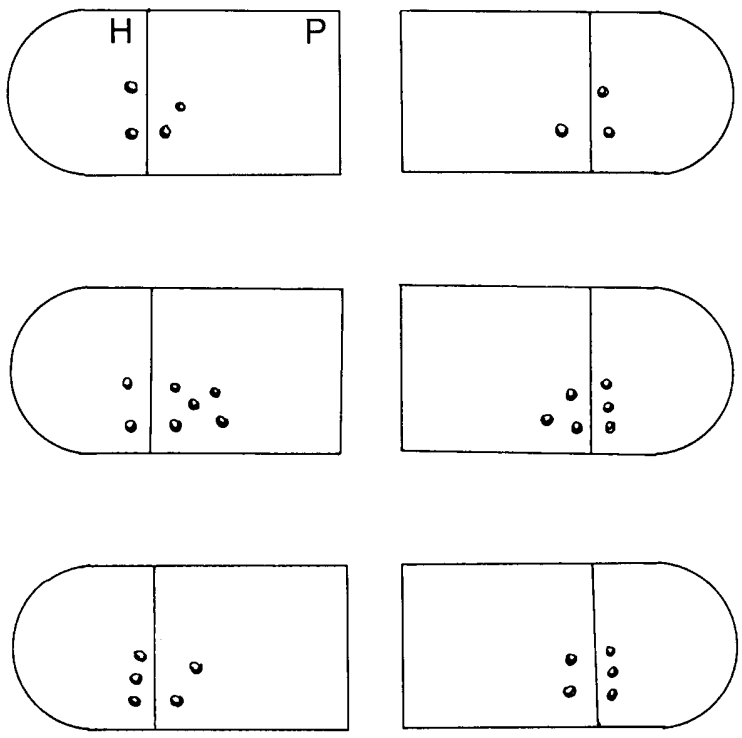

Fig. 19. Anomalipus plebejus plebejulus, patterns of distribution of the deep pits on left and right sides of head and pronotum of three available later instar larvae. $\mathrm{H}-$ head, $\mathrm{P}-$ prothorax.

Thorax. Uniformly brown, only pronotum darker. Prothorax subquadrate, 2 times longer than meso- or metathorax; laterally just before anterior margin with $1-5$ deep pits (Figs 19, 23, 24). Mesothoracic spiracle elongateovate, twice diameter of first abdominal spiracle (Fig. 12). Median suture clearly visible as a white line on all three nota. Fore legs longer and stouter than mid and hind legs, setal arrangement as in Figs 15 and 16. Fore leg with coxae subquadrate and strongly prominent; trochanter elongated, anteriorly with two heavily sclerotized tubercles (joined at base); femur elongated, from $2 / 3$ narrowing apicad with two heavily sclerotized tubercles on basal 1/3 (separated at base); tibia elongated; tarsungulus simple, somewhat shorter than tibia. Mid and hind legs as in Figs 17-18.

Abdomen. Sides of first eight segments nearly parallel, terga subquadrate, as long as pronotum. Ninth tergum elongated, longer than its greatest width, conically expanded also ventrally, sides tapering apically, without spines. Pleurosternal suture visible. Ninth sternum extremely reduced; pygopodia visible only at base, with weakly pointed apices (Figs 25-26). Spiracles small, rounded.

Egg and first instar. Egg elongate-ovate, whitish, 3.6 $\mathrm{mm}$ long, $2.1 \mathrm{~mm}$ wide. Chorion without any peculiar structures visible under $\times 100$ magnification. Body of first-instar larvae ivory-white, 8.8 and $9.6 \mathrm{~mm}$ long, 1.5 and $1.6 \mathrm{~mm}$ wide, head-capsule 1.1 and $1.2 \mathrm{~mm}$ broad. Body subcylindrical, pronotum is the longest segment (Fig. 20). Second antennomere widest distally, 1.2 times longer than wide, obviously enlarged compared with older instars. A pair of egg-bursters in form of spines near median setae (Fig. 14) present from pronotum to eighth abdominal tergum, increasing somewhat in size posteriorly. Ninth abdominal segment without egg-bursters near medial setae, but apex has two small, apically sclerotized, and divergent egg-burster-like cerci; ninth abdominal tergum broadly cordate with two additional setae laterally on anterior quarter and two near apex; ninth abdominal sternum reduced, pygopodia small. Apices of mandibles and tips of tarsungulus weakly sclerotized. Stemmata, setae and tubercles of legs correspond in number and position to those of later instars.

Material examined. $1 \mathrm{egg}, 2$ first instar larvae, and 3 larvae of later instars (the largest $26.2 \mathrm{~mm}$ long, $2.9 \mathrm{~mm}$ wide, head capsule $2.6 \mathrm{~mm}$ broad). Parents of these immatures were collected in Zimbabwe, $50 \mathrm{~km}$ South of Bulawayo, northern boundary of Matobo National Park, 3.-5.xii.1998 (lgt. S. Bečvář), and bred in Czech Republic at room temperature in a 4 $\mathrm{dm}^{3}$ container half-full of a mixture of rotted oak wood and oak leaf litter starting from 25.xii.1998. Only the adults fed on the banana diet. The last larva was collected 29.i.1999 (36th day). The larvae and egg were killed and preserved for several months in Pampel's fluid (mixture of water, $96 \%$ ethanol, $40 \%$ formaldehyde and concentrated acetic acid in ratio $30: 15: 6: 4$ ). Finally the material was transferred to $96 \%$ ethanol and is stored in Stanislav Bečvář collection (larval register no.122).

Comments. The descriptions of the early instars of Anomalipus plebejus plebejulus confirm Schultze's opinion (1963) that Anomalipus larvae are characterised by a reduced ninth sternum (very small pygopodia) and the presence of deep pits on the head and pronotum. The antennal composite sensillum on the apex of segment 2 of A. plebejus plebejulus (composed of 6 rounded portions around the base of segment 3) differs from that of Anomalipus species studied by Schulze. In 1978 she noticed that an antennal sensillum of Anomalipus larvae has a convoluted enlarged surface comparable only to that of the subgenus Agonopus Gebien. The other larvae of Platynotini possess an open-annular antennal sensillum (an incomplete ring around the base of segment 3 ).

\section{DISCUSSION}

Skopin $(1962,1964)$ published a larval classification of the world Tenebrionidae and related families. In spite of the objection that he introduced the "morpha" groups, his identification keys as well as his interpretations of particular groups and their distinctive characters are still used. On the basis of the structure of the fore legs, caudal segment, mouthparts and antennae, this author distinguished the following categories: (1) Pedobionta (Tentyromorpha, Asidomorpha, Blapimorpha), (2) Heterobionta (Ulomimorpha - containing Alleculidae, Tenebriomorpha, Phrenapatimorpha, Diaperimorpha), (3) Boletophaginae, (4) Nilionidae, (5) Lagriidae, and (6) Pycnocerimorpha.

When larvae of Anomalipus are identified with Skopin's (1964) key, they fall either into Pedobionta or Heterobionta. Based on adult morphology, there is no doubt that Anomalipus belongs to the opatrinoid lineage (Opatrinae sensu Medvedev, 1968) of the Tenebrioninae. In Skopin's key the larvae of opatrines have the characterstics of both Pedobionta and Blapimorpha. Such features are (also in Anomalipus) the absence of urogomphi and enlarged, prominent, digging forelegs with tubercles and asymmetrical chaetotaxy. On the other hand, the 


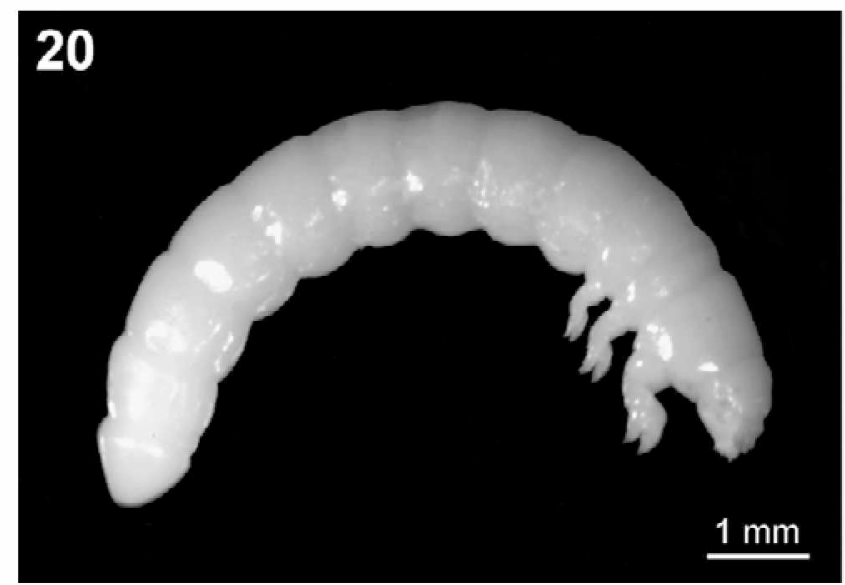

21
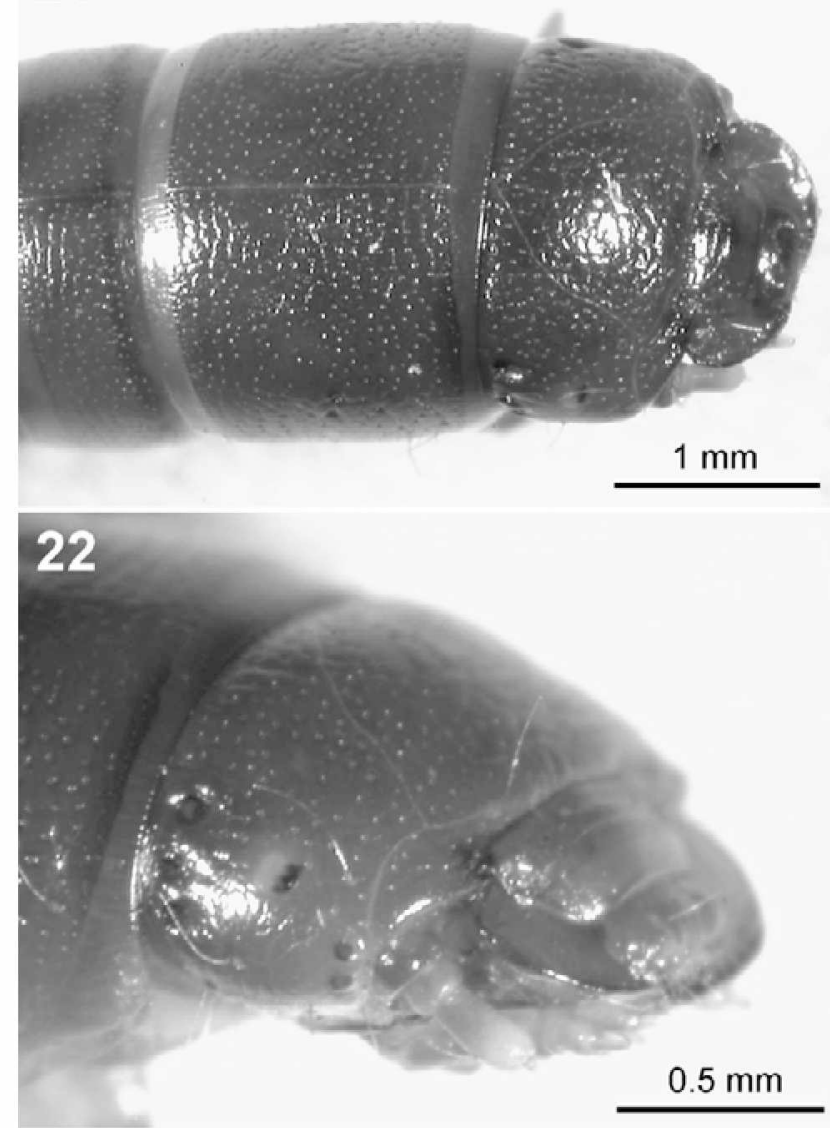

26

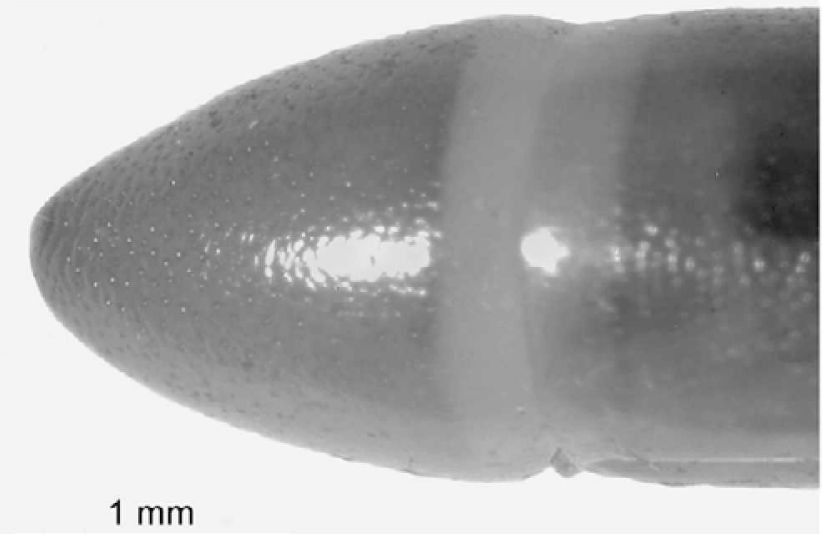

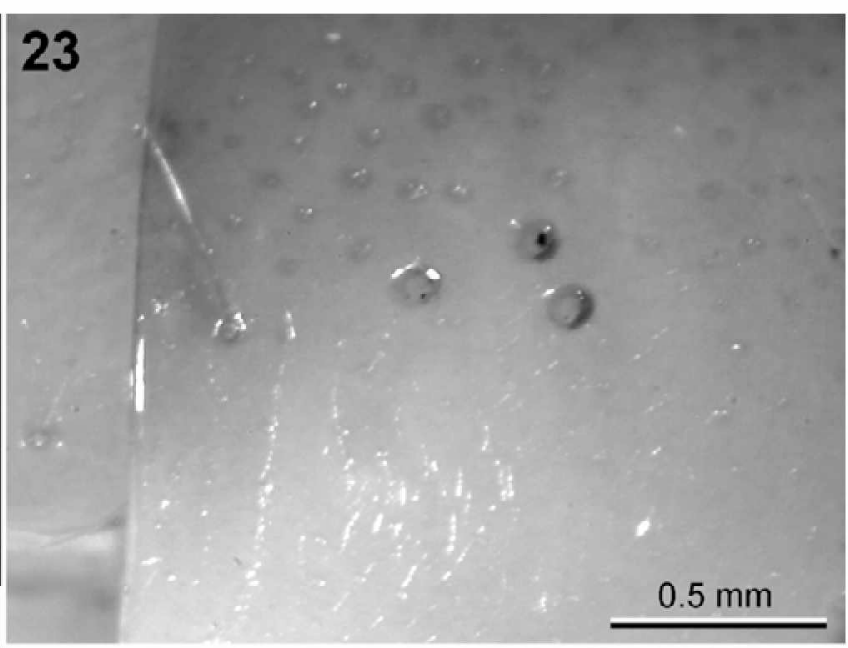

\section{4}

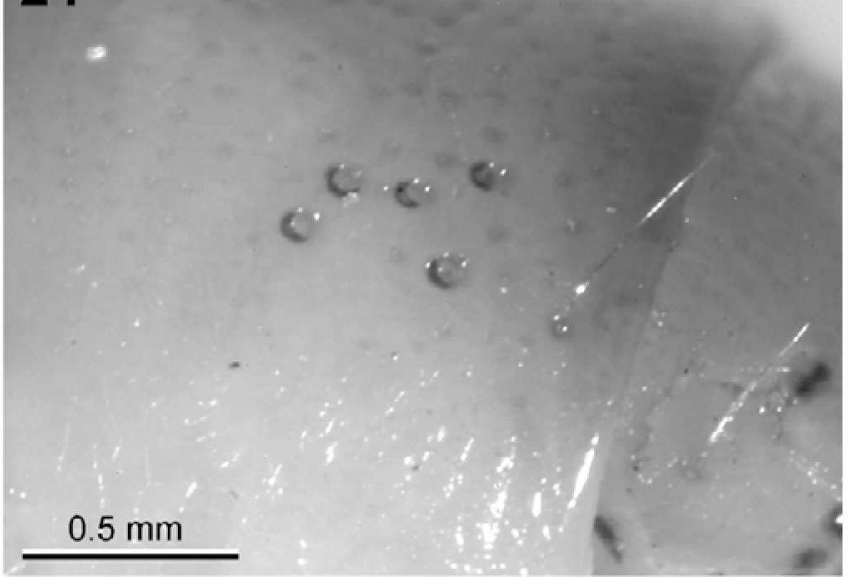

25

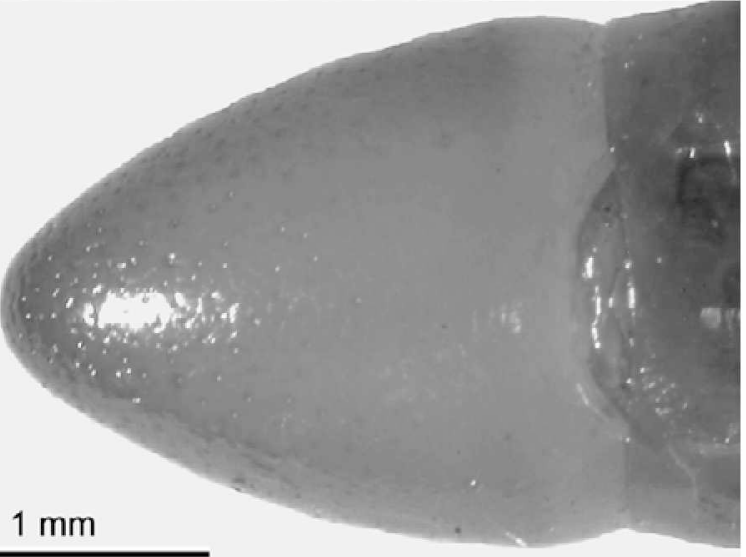

Figs 20-26: Anomalipus plebejus plebejulus. 20 - first instar, total view; 21 - head, pro- and mesonotum, dorsal view; 22 - head, lateral view; 23 - left and 24 - right sides of prothorax; 25 - ventral and 26 - lateral view of ninth abdominal segment. 
undivided tarsungulus in Anomalipus is typical of Heterobionta. This incongruity needs explanation because its placement into Blapimorpha is justified by the structure of abdominal segment IX (ventral part of the tergum larger than its dorsal part) and of the hypopharyngeal sclerome (trilobed). In addition placing this genus in Heterobionta raises other incongruities.

After Skopin only Watt (1974) has dealt with tenebrionid larvae on a world basis. In Watt's key the larva of Anomalipus keys out to the subfamily Tenebrioninae and the group "Blapimorpha" after Skopin (1964). However, the Blapimorpha is diagnosed differently in each of the two publications. In Skopin, it is based on the forelegs adapted for digging (diagnosis of Pedobionta), enlarged size and tarsungulus composed of two parts, and chaetotaxy. Watt simplifies the leg description to "legs modified for digging", stresses the structure of the tarsungulus (bipartite) and adds a character which is not mentioned in Skopin's paper: "Outer dorsolateral edge of mandible with a membranous, setose elevation near base" (p. 449, Fig. 91). Watt's key does not place Anomalipus and some other taxa of Opatrinae in the Blapimorpha.

In the following paragraphs the features used in the larval classification of Opatrinae, which are also found in Anomalipus are discussed. Notes on the other conspicuous characteristics of this genus are added.

Both above mentioned authors regard the structure of tarsungulus as a critical feature of the larvae of Blapimorpha but it is variable in Opatrinae. The illustrations of Keleinikova $(1966,1968)$ and Hayashi $(1966,1968)$ indicate that the genera Penthicus (syn. Lobodera), Melanesthes (Opatrini), Aphaleria, Dissonomus (Dissonomini), Cabirutus (Pedinini) and Caedius, Mesomorphus and Gonocephalum (Opatrini) have an undivided tarsungulus. We can confirm this for Gonocephalum as we have found it in a larva from Zimbabwe. Marcuzzi \& Rampazzo (1960) record undivided tarsungulus in Opatrum (Opatrini), but this needs to be confirmed because they also drew numerous Pimeliinae (Tentyromorpha of Skopin's system) with tarsungulus undivided except in Akis italica. It is likely that these authors ignored this feature. The division of the tarsungulus was probably particularly obvious in the case of $A$. italica, and hence was drawn and also mentioned in the description of this species (except for forelegs). Nevertheless, the clear drawings of Costa et. al. (1988) record an undivided tasungulus in Scotinus sp. (Pimeliinae). In Platynotini, two taxa, the subgenus Agonopus (Schulze, 1978) and Anomalipus, possess an undivided tarsungulus. The taxonomic significance of a divided tarsungulus (derived condition) seems to be weak because this feature evolved independently many times in larvae digging in the soil as suggested above. Lawrence \& Medvedev (1982) also came to a similar conclusion about taxa of the tentyrioid branch.

The structure of the caudal segments has always been decisive for larval tenebrionid classification, and is very characteristic in Anomalipus. A similar paraboloid and smooth tergum IX (without spines or urogomphi) com- bined with striking reduction of the sternum occurs in Alleculinae and in the genus Uloma (Diaperinae). Watt (1974) stated that the resemblances between the larvae of Uloma and Alleculidae (in Skopin's system they both belong to Ulomimorpha) are probably due to convergence. We propose that the same may apply to the genus Anomalipus and Ulomimorpha. One character, the absence of spines at the end of abdominal tergum IX in Anomalipus is unique as far as we know in the opatrine lineage and may be regarded as an advanced character (secondary disappearance). Four abdominal spines are present in larvae of the subtribe Platynotina (Schulze, 1964; Iwan, 1995) except in the tentative Pseudoblaps ampliata described by Skopin (1972). This larva has about twenty spines arranged semicircularly on the apical margin of tergum IX and differs from all known Platynotini also by having three stout and sclerotised setae on pseudopods. We agree with Skopin's opinion that this immature tenebrionid belongs to the Blapimorpha, but its placement in Platynotyni is not secure as it is similar to larvae of the genus Gonocephalum (Opatrini). In the subtribe Gonopina the spines at the end of abdominal tergum IX vary from two to six between and within species. Four spines were found in the tribes Scaurini, Crypticini, Pedinini, (Schulze, 1969; Skopin, 1978), Platynotini (Schulze, 1964, 1969; Iwan, 1995), Dissonomini, Dendarini (Keleinikova, 1966), Diaperini (Hayashi, 1968) and Phaleriini (Costa et al., 1988; Carl, 1995). All these tribes have been assigned recently to the tenebrionine and diaperine lineages of the tenebrionoid branch. The presence of this morphological feature even in distant taxa which have completely different adults is surprising. If the spines of these genera are homologous we can agree with Schulze (1969) that this condition is plesiomorphic.

According to Watt's (1974) key to the subfamilies of Tenebrionidae, the larvae of Pimeliinae bear numerous setae on the dorsolateral mandibular membranous elevation (dmme), whereas in Alleculinae and Tenebrioninae, if present a dmme may only bear a few setae. Among Tenebrioninae the Blapimorpha in this key have a setose dmme. As far as we are aware in Opatrinae, the density of setae on the dmme and also the presence of a dmme vary considerably. Single setae on the dmme are common for larvae of Platynotina and Anomalipina, but in Quadrideres and Bantodemus (Schulze, 1964) and Anomalipus (this paper) the d.m.m.e is indistinct because of its sclerotization. In Gonopina (Schulze, 1978) and Stizopina (Schulze, 1963), it has numerous setae. Hence this feature must be rejected as diagnostic of the Blapimorpha in the sense of Watt (1974) but could be used in a future key with the reservation that it does not pertain to all taxa (the same applies to the undivided tarsungulus, see above).

Doyen \& Tschinkel (1982) used the dmme in a phylogenetic analysis of Tenebrionidae. In the tenebrionoid branch, one of the groups they distinguished is the opatrine lineage, including the subfamily Opatrinae sensu Medvedev (1968) with Helopini and Ulomini sensu Gebien (1938-1939). They understood the tribe Opatrini much more broadly than previous authors and include 
TABLE 1. Tribal classification of the subfamily Opatrinae sensu Medvedev (1968) compared with those of other authors (1937-1993).

\begin{tabular}{|c|c|c|c|c|c|c|c|c|}
\hline $\begin{array}{c}\text { Gebien } \\
1937-1939\end{array}$ & $\begin{array}{l}\text { Koch } \\
1956\end{array}$ & $\begin{array}{c}\text { Medvedev } \\
1968\end{array}$ & $\begin{array}{c}\text { Doyen } \\
1972\end{array}$ & $\begin{array}{l}\text { Watt } \\
1974\end{array}$ & $\begin{array}{c}\text { Doyen \&Tschinkel } \\
1982\end{array}$ & $\begin{array}{c}\text { Aalbu \& Triplehorn } \\
1985 \\
\text { (North America) }\end{array}$ & $\begin{array}{c}\text { Doyen et al. } \\
1990 \\
\text { (Australia) }\end{array}$ & $\begin{array}{c}\text { Doyen } \\
1993\end{array}$ \\
\hline Pedinini* & Dendarini & Dendarini & - & - & **opatrine: Opatrini & - & - & - \\
\hline Opatrini* & Leichenini & Leichenini & - & - & **opatrine: Opatrini & $\begin{array}{l}\text { Tenebrioninae: } \\
\text { Leichenini }\end{array}$ & $\begin{array}{c}\text { Tenebrioninae: } \\
\text { Leichenini }\end{array}$ & - \\
\hline Pedinini* & Loensini & Loensini & - & - & $* *$ opatrine: Opatrini & - & - & - \\
\hline $\begin{array}{l}\text { Pedinini* } \\
\text { Opatrini* }\end{array}$ & Litoborini & Litoborini & - & - & **opatrine: Opatrini & - & - & - \\
\hline Helopinini* & & & & & & & & \\
\hline $\begin{array}{l}\text { Platyscelini* } \\
\text { Gonopini* } \\
\text { Pedinini* } \\
\text { Opatrini* }\end{array}$ & Oncotini & Oncotini & - & - & ${ }^{* *}$ opatrine: Opatrini & - & - & - \\
\hline $\begin{array}{c}\text { Helopinini* } \\
\text { Gonopini** } \\
\text { Opatrini* } \\
\text { Pedinini* }\end{array}$ & Platynotini & Platynotini & - & - & **opatrine: Opatrini & $\begin{array}{l}\text { Tenebrioninae: } \\
\text { Platynotini }\end{array}$ & - & - \\
\hline Pedinini* & Pedinini & Pedinini & - & - & **opatrine: Opatrini & - & - & - \\
\hline Stenosini* & Pythiopini & Pythiopini & - & - & **opatrine: Opatrini & - & - & - \\
\hline Opatrini* & Melanimini & Melanimini & - & - & **opatrine: Opatrini & $\begin{array}{c}\text { Tenebrioninae: } \\
\text { Melanimini }\end{array}$ & - & - \\
\hline Pedinini* & - & Dissonomini & - & - & **opatrine: Opatrini & - & - & - \\
\hline Pedinini* & Opatrini* & Pachypterini & - & - & **opatrine: Opatrini & - & - & - \\
\hline Pedinini* & Heterocheirini & Heterocheirini & - & - & **opatrine: Opatrini & - & $\begin{array}{l}\text { Tenebrioninae: } \\
\text { Heterocheirini }\end{array}$ & - \\
\hline $\begin{array}{l}\text { Opatrini* } \\
\text { Gonopini* } \\
\text { Pedinini* }\end{array}$ & Opatrini* & Opatrini & - & - & **opatrine: Opatrini & $\begin{array}{c}\text { Tenebrioninae: } \\
\text { Opatrini }\end{array}$ & $\begin{array}{c}\text { Tenebrioninae: } \\
\text { Opatrini }\end{array}$ & - \\
\hline Heterotarsini* & Heterotarsini* & $\begin{array}{l}\text { Heterotarsini* } \\
\text { (Heterotarsus) }\end{array}$ & - & $\begin{array}{c}\text { Opatrini } \\
\text { (Heterotarsus) }\end{array}$ & $\begin{array}{l}\text { **opatrine: Opatrini } \\
\text { (Heterotarsus) }\end{array}$ & - & - & - \\
\hline Heterotarsini* & Heterotarsini* & Heterotarsini* & - & Lagriinae* & $\begin{array}{c}\text { lagriine: Goniaderini, } \\
\text { Lupropini; } \\
\text { belopine (?); }\end{array}$ & - & Lagriinae* & - \\
\hline Physogasterini & - & Physogasterini & Tentyriidae & Tentyriinae & $\begin{array}{c}\text { Tentyriine: } \\
\text { Physogasterini }\end{array}$ & Tentyriinae & - & Pimeliinae \\
\hline Praocini & - & Praocini & Tentyriidae & Tentyriinae & Tentyriine: Praocini & Tentyriinae & - & Pimeliinae \\
\hline Branchini & - & Branchini & Tentyriidae & Tentyriinae & - & Tentyriinae & - & Pimeliinae \\
\hline Coniontini & - & Coniontini & Tentyriidae & Tentyriinae & $\begin{array}{l}\text { Tentyriine: } \\
\text { Coniontini }\end{array}$ & Tentyriinae & - & Pimeliinae \\
\hline Coelini & - & Coelini & Tentyriidae & Tentyriinae & - & Tentyriinae & - & Pimeliinae \\
\hline
\end{tabular}

** tribes listed collectively as Opatrinae sensu Medvedev (1968)

* part

- not mentioned

Only bold typed tribes in Medvedev's classification belong to Opatrinae (= Tenebrioninae in modern studies).

genera otherwise classified in the tribes Eleodini, Helopinini, Opatrini and Pedinini sensu Gebien (1937, 1938-1939). In the cladogram based on 38 selected characters (Doyen \& Tschinkel, 1982, p. 149, Fig. 50) the sole synapomorphy of the opatrinae lineage is the structure of the ovipositor and among three apomorphies, one larval character (no. 74) "the mandible, base with setose membrane" seems to be the most controversial. On p. 145 the authors describe it briefly: "In Tentyriinae the mandibles bear a tuft of stout setae dorsally at the base", and in Appendix B (Character state matrix) they attribute the derived state of the character (its presence) to Opatrini, Pimeliini and Tentyriini. Watt (1974) gives the distribution of this feature among subfamilies of Tenebrionidae in his Table 5 and states that a dmme bearing numerous setae is only found in Pimeliinae. We found that Lagriinae species also have mandibles with numerous setae as figured by Skopin (1964) (Pycnocerini), Hayashi (1968) (Lagriini, Lupropini), Arndt (1993) (Lupropini), and
Costa et al. (1988) (Goniaderini). The drawings of the larva of the genus Goniadera shows a remarkable membranous elevation. Costa et al. (1988) also describe a larva of Tauroceras aries (Coelometopinae: Coelometopini) that possesses more than twenty mandibular setae but lacks a dmme and state that the larva of Scotinus sp. (Pimeliinae: Asidini) is similar in this, which probably represents the first record of a missing dmme among Pimeliinae. We are not going to discuss the question of the polarity of the dmme but its presence among species of both soil and wood dwellers may suggest a groundplan character of Tenebrionidae.

Keleinikova (1968) presented observations on the changes in the chetotaxy of the labrum and dorsolateral area of the mandible in various juvenile stages. Watt (1992) ignores her conclusions and writes: "Far too few first-instar larvae of either the tentyrioid or the tenebrionoid lineage are known to permit evaluation of the significance of number of setae." 
In species of the opatrine lineage, the gular sutures usually extend to the occipital foramen and such a condition is common in Tenebrionidae except Phrenapatinae. Hayashi (1966) reports that the gula and epicranium fuse completely in Palorus (Ulomini) and gular sutures are indistinct in Latheticus (Ulomini). In the genus Anomalipus the gular sutures are short and do not reach the occipital foramen, which can be interpreted as a secondary shortening (derived condition). In the remaining Platynotini larvae, the gular sutures are fully developed.

In Opatrinae, the antennal sensillum of the second segment usually looks like an open ring around the base of the apical segment (primitive condition). In Platynotini, the development of the antennal sensillum is variable within the genera Gonopus and Anomalipus. Schulze (1978) reported the primitive condition in the subgenus Gonopus but an irregularly convoluted, enlarged sensillum in Agonopus. In the same paper she mentioned a similar convoluted sensillum in Anomalipus. As we have found in A. plebejus plebejulus, the sensillum is composed of a regular circlet of six subtriangular parts and may represent the most derived state of this sensory organ so far known in Opatrinae.

One pair of egg-bursters on the tergum of the mesoand metathorax and each abdominal tergum up to segment VIII represents a common pattern in first-instar larvae in Opatrinae according to Medvedev (1968). As far as we are aware, only the genera Anomalipus and Gonopus possess pronotal egg-bursters. In addition, Anomalipus possesses an egg-burster-like divergent cerci on the apex of abdominal segment IX. This condition seems to be unique in Opatrinae, although it may be homologous with the bifurcate apex of the caudal segment in Pedinus (Pedinini) (Medvedev, 1968). In the paper by Schulze (1963), first-instar larvae of three genera of Stizopina were described, each with a special pattern of egg-bursters. The first instars of Tenebrionidae are too poorly known to permit an evaluation of the significance of this character for taxonomy.

\section{CONCLUSION}

At present, because of the scarcity of data, it appears that larval characters are useful for definition and phylogenetic analysis of only some taxa, rather than for a complete phylogenetic analysis. It is impossible to define the tribal characteristics of Platynotini larvae when only about five percent of larvae are known. The strict association between the structure of larvae and the habitat they live in results in different species having similar characters (Schulze, 1964, 1969). For this reason results of phylogenetic analyses are very difficult to interpret (there is a high number of homoplasies), and the characters are of greater value for constructing keys than for defining monophyletic taxa.

The classification of the Tenebrionidae is still based mainly on adult characters. In 1974 Watt, when distinguishing tenebrionid subfamilies, analysed 21 adult and 15 preimaginal characters, while Doyen \& Tschinkel (1982) used 80 characters only 7 of which are larval. The world identification keys for tenebrionid larvae contained in the papers of Skopin $(1964,1978)$ and Watt (1974) are only useful for separating of Opatrinae larvae from other tenebrionids if the reservations mentioned in this paper are considered.

The tribal classification of the subfamily Opatrinae sensu Medvedev (1968) compared with those of other authors (1937-1993) is presented in Table 1. A modification of the concept of Blapimorpha is necessary to accommodate the new findings on Anomalipus and also several other genera. Considering the obvious disparity between existing larval and adult taxonomy and our limited knowledge of larval forms, radical changes in the classification of Tenebrionidae can be expected.

ACKNOWLEDGEMENTS. We thank S.A. Ślipiński for his help during the preparation of this paper and to anonymous reviewers for they valuable suggestions. The paper was partly sponsored by the State Committee for Scientific Research (Komitet Badań Naukowych, Warsaw, Poland), grant no. 6 P04C 07412.

\section{REFERENCES}

Aalbu R.L. \& Triplehorn C.A. 1985: Redefinition of opatrine tribes in North America with notes on some apterous genera (Coleoptera: Tenebrionidae: Tenebrioninae). Coleopts. Bull. 39: $272-280$.

ARNDT E. 1993: Description of the larva Anaedus camerunus Gebien (Coleoptera: Tenebrionidae, Lupropini). Koleopt. Rdsch. 63: 273-277.

CARL M. 1995: Die Präimaginalstadien der Tenebrionidae 2. Beschreibung der Larven von Mesostena picea Kraatz und Phaleria prolixa Fairmaire aus Ägypten (Coleoptera: Tenebrionidae). Koleopt. Rdsch. 65: 193-200.

Costa C., Vanin S. \& Casari-Chen S. 1988: Larvas de Coleoptera do Brasil. Museu de Zool., Univ. Săo Paulo, 282 pp.

DOYEN J.T. 1972: Familial and subfamilial classification of the Tenebrionoidea (Coleoptera) and a revised generic classification of Coniontini (Tentyriidae). Quaest. Entomol. 4: 333-377.

DOYEN J.T. 1993: Cladistic relationships among pimeliine Tenebrionidae (Coleoptera). J. N. Y. Entomol. Soc. 101: 443-514.

DOYEN J.T. \& TSCHINKEL W.R. 1982: Phenetic and cladistic relationships among tenebrionid beetles (Coleoptera). Syst. Entomol. 7: 127-183.

Doyen J.T., Matthews E.G. \& Lawrence J.F. 1990: Classification and annotated checklist of the Australian genera of Tenebrionidae (Coleoptera). Invert. Taxon. 3: 229-260.

ENDRödy-Younga S. 1988: Revision of the Genus Anomalipus Latreille, 1846 (Coleoptera: Tenebrionidae: Platynotini). Transvaal Museum Monograph No. 6. Transvaal Museum, Pretoria, $129 \mathrm{pp}$.

GeBIEn H. 1937: Katalog der Tenebrioniden. Teil I. 6. Museo Entomologico "Pietro Rossi”, Duino, pp. 679-692.

Gebien H. 1938-39: Katalog der Tenebrioniden. Teil II. 7. Mitt. Münch. Entomol. Ges. 28(1): 49[370]-80[401], 283[402]-428 [465]; 29(2,3): 443[466]-474[497].

HAYASH N. 1966: A contribution to the knowledge of the larvae of Tenebrionidae occurring in Japan. (Coleoptera: Cucujoidea). Insecta Matsum. (Suppl. 1), 41 pp., 32 pls.

HAYASHI N. 1968: Additional notes on the larvae of Lagriidae and Tenebrionidae occurring in Japan (Coleoptera: Cucujoidea). Insecta Matsum. (Suppl. 3), $12 \mathrm{pp.}$

IwaN D. 1995: Revision of the genus Opatrinus Dejean, 1821 (Coleoptera: Tenebrionidae: Platynotini). Genus 6: 1-90. 
JACK R.W. 1917: Notes on the larvae, etc., of some Rhodesian Tenebrionidae. S. Afr. J. Nat. Hist. 1: 84-98

Keleinikova S.I. 1966: Descriptions of larvae of some Palearctic genera of darkling beetles of the tribe Pedinini (Coleoptera, Tenebrionidae). Entomol. Obozr: 45: 589-598 (in Russian).

KeleinIKova S.I. 1968: Soil-inhabiting darkling beetle larvae (Coleoptera, Tenebrionidae) in the Soviet fauna. Sb. Trudov Zool. Muz. Moskov. Gosud. Univ. 11: 205-239 (in Russian).

Косн C. 1956: II. Tenebrionidae (Coleoptera, Polyphaga), Opatrinae, First part: Platynotini, Litoborini and Loensini. Explor. Parc Natn. Upemba (Bruxelles) 40: 472 pp.

LAWRENCE J.F \& MEDVEDEV G.S. 1982: A new tribe of darkling beetles from Australia and its systematic position (Coleoptera, Tenebrionidae). Entomol. Rev. 61: 85-107.

Marcuzzi G. \& Rampazzo L. 1960: Contributo alla conoscenza delle forme larvali dei Tenebrionidi (Coleoptera, Heteromera). Eos 36: 63-117.

Medvedev G.S. 1968: Darkling-Beetles (Tenebrionidae), Subfamily Opatrinae. The Tribes Platynotini, Dendarini, Pedinini, Dissonomini, Pachypterini, Opatrini (part) and Heterotarsini Fauna USSR 19, Academy of Sciences of the USSR, Leningrad, 285 pp. (in Russian).

Péringuey L. 1896: Descriptions of new genera and species of Coleoptera from South Africa, chiefly from Zambezia. Trans. R. Entomol. Soc. Lond. 2: 149-189.

Schulze L. 1962: The Tenebrionidae of Southern Africa XXXIII. Description of the larv ae of Gonopus tibialis Fabricius and Gonopus agrestis Fahraeus (Gonopina, sensu Koch 1956). Cimbebasia 5: 1-12.

Schulze L. 1963: The Tenebrionidae of Southern Africa XXXVIII. On the morphology of the larvae of some Stizopina (Coleoptera: Opatrini). Scient. Pap. Namib Desert Res. Stn. 19: $1-23$.

Schulze L. 1964: The Tenebrionidae of Southern Africa XXXVI. Descriptive notes and key to the larvae of Zophodes fitzsimonsi Koch, Bantodemus zulu Koch and Quadrideres femineus (Lesne) (Coleoptera: Platynotina s. str.). J. Entomol. Soc. Sth. Afr. 26: 441-451.
Schulze L. 1968: The Tenebrionidae of Southern Africa. XLI. Descriptive notes on the early stages of four genera of the tribe Drosochrini (Coleoptera). Ann. Transv. Mus. 26: 31-51.

Schulze L. 1969: The Tenebrionidae of Southern Africa. XLII. Description of the early stages of Carchares macer Pascoe and Herpiscus sommeri Solier with a discussion of some phylogenetic aspects arising from the incongruities of adult and larval systematics. Scient. Pap. Namib Desert Res. Stn. 53: 139-149.

Schulze L. 1974: The Tenebrionidae of Southern Africa. XLIII. Description of some larvae of the Zophosini with observations on the possible origin of phylogenetic evolution of dune-living genera (Coleoptera). Ann. Transv. Mus. 29: 71-98.

SChulze L. 1978: The Tenebrionidae of Southern Africa. XLV. Description of some larvae of the subgenera Gonopus and Agonopus of the genus Gonopus (Coleoptera). Ann. Transv. Mus. 31: 1-16.

Skopin N.G. 1962: Larvae of the subfamily Pimeliinae (Coleoptera, Tenebrionidae). Trudy nauchno-issled. Inst. Zashch. Rast. (Kazakhstan) 7: 191-298 (in Russian).

Skopin N.G. 1964: Die Larven der Tenebrioniden des Tribus Pycnocerini (Coleoptera, Heteromera). Ann. Mis. R. Afr. Cent. (Serie 8vo) (Tervuren) 127: 1-35.

SkopıN N.G. 1972: Über einige Tenebrioniden-Larven aus Nepal nebst übersicht der bekanntesten Larven der primitiven BlapsArten (Ins., Coleoptera). Khumbu Himal Innsbruck-München 4: $315-321$.

SkopIN N.G. 1978: Tenebrionidae. In Klausnitzer B. (ed.): Ordnung Coleoptera (Larven). Akademie-Verlag, Berlin, pp. 223-248.

Watт J.C. 1974: A revised subfamily classification of Tenebrionidae (Coleoptera). N. Z. J. Zool. 1: 381-452.

Watт J.C. 1992: Relationships of Actizeta and Cnemeplatiini (Coleoptera: Tenebrionidae). Syst. Entomol. 17: 287-299.

Received March 27, 2000; accepted June 22, 2000 